\title{
Antioxidant and immunostimulatory activities of polysaccharides extracted from Tremella aurantialba mycelia
}

\author{
CHAO DENG ${ }^{1-3}$, YUANYUAN SUN ${ }^{2}$, HAITIAN FU ${ }^{2}$, SIXIU ZHANG ${ }^{1}$, JINGHUA CHEN $^{2}$ and XIN XU ${ }^{4}$ \\ ${ }^{1}$ Wuxi Medical School and ${ }^{2}$ School of Pharmaceutical Science, Jiangnan University, Wuxi, Jiangsu 214122; \\ ${ }^{3}$ Key Laboratory of Industrial Biotechnology, Ministry of Education, Jiangnan University, Wuxi, Jiangsu 214122; \\ ${ }^{4}$ Cardiovascular Department, Wuxi No. 2 People's Hospital, Wuxi, Jiangsu 214002, P.R. China
}

Received September 15, 2015; Accepted August 23, 2016

DOI: $10.3892 / \mathrm{mmr} .2016 .5794$

\begin{abstract}
In the present study, the physiochemical and biological properties of crude mycelium polysaccharide (CMCP) and purified mycelium polysaccharide (MCP) extracted from the Tremella aurantialba mycelium were investigated. A series of physiochemical properties were determined, including the total sugar, uronic acid and protein content, monosaccharide composition and structure, and molecular weight. The reducing power and scavenging activity of 2,2-diphenyl-1-picrylhydrazyl (DPPH) and hydroxyl radicals were determined to investigate the antioxidant activity of CMCP and MCP. Furthermore, the immunostimulatory activity of the polysaccharides was evaluated by detecting the effects of CMCP and MCP on proliferation, nitric oxide (NO) production and cytokine secretion by RAW264.7 cells. The chemical analysis revealed that MCP had a molecular weight of $4.3 \times 10^{4} \mathrm{~g} / \mathrm{mol}$ and was composed primarily of D-glucose, D-galactose and D-mannose. The total carbohydrate contents of MCP and CMCP were 86.59 and $11.92 \%$, respectively. Compared with CMCP, MCP demonstrated improved antioxidant properties. In addition, MCP induced RAW264.7 macrophage proliferation, NO production and secretion of tumor necrosis factor- $\alpha$, interleukin (IL)-1 and IL-6. These findings suggest that the total carbohydrate content may contribute to the improvement of antioxidant and immunostimulatory activities of MCP.
\end{abstract}

Correspondence to: Professor Jinghua Chen, School of Pharmaceutical Science, Jiangnan University, 1800 Lihu Road, Wuxi, Jiangsu 214122, P.R. China

E-mail: jscdcdjl@163.com

Ms. Xin Xu, Cardiovascular Department, Wuxi No. 2 People's Hospital, 68 Zhongshan Road, Wuxi, Jiangsu 214002, P.R. China E-mail: xinfirst1@163.com

Key words: Tremella aurantialba mycelium polysaccharide, antioxidant activity, immune enhancement activity

\section{Introduction}

Tremella aurantialba, a wood-inhabiting host-specific fungus, has been commonly used in traditional Chinese medicine (1). Numerous studies have analyzed polysaccharides extracted from its mycelium and fruit body as well as the crude extract of the fermentation broth (2-4). These extracted polysaccharides have been demonstrated to have pharmacological properties, including antidiabetic, antitumor and antihyperlipidemic activities (5-7), as well as immunostimulatory effects (8). Kiho et al (9) revealed that a polysaccharide isolated from $T$. aurantialba produced significant antidiabetic effects, and decreased serum cholesterol, free fatty acid and triglyceride levels in diabetic mice. Furthermore, polysaccharides extracted using hot water and ethanol (70\%) from T. aurantialba exerted potent inhibitory effects on the growth of prostate cancer cell lines, including LNCaP and PC-3 (10). Therefore, T. aurantialba polysaccharides may be valuable sources of food and pharmaceutical agents.

To date, the extraction of polysaccharides from T. aurantialba has not been commercially feasible. This is largely due to a long cultivation cycle and low production, as well as sensitivity to seasons and insects. To address these issues, liquid fermentation technology has been adopted to increase the yield of $T$. aurantialba and its polysaccharide content.

Numerous studies have investigated the biological functions of mycelium polysaccharides from T. aurantialba in cardiovascular and cerebral diseases, diabetes mellitus, and in blood fat and pressure control $(2,11,12)$. However, little is known about the antioxidant and immunostimulatory activities of mycelium polysaccharides. In the present study, crude mycelium polysaccharide (CMCP) and purified mycelium polysaccharide (MCP) were isolated from the mycelia of T. aurantialba using liquid fermentation technology. The antioxidant activities of these polysaccharides were evaluated by determining their reducing power, and 2,2-diphenyl-1-picrylhydrazyl (DPPH) and hydroxyl radical scavenging ability. Furthermore, immunostimulatory effects were analyzed by investigating cellular proliferation, and the release of nitric oxide (NO), tumor necrosis factor- $\alpha$ (TNF- $\alpha$ ), interleukin (IL)-1 and IL-6 by RAW264.7 macrophages. 


\section{Materials and methods}

Materials. T. aurantialba was purchased from The Agricultural Culture Collection of China (Beijing, China). The RAW264.7 mouse macrophage cell line was obtained from the cell bank of The Chinese Academy of Sciences (Shanghai, China). Dimethyl sulfoxide (DMSO), 3-(4,5-dimethylthiazol-2-yl)-2,5-diphenyltetrazolium bromide (MTT), DPPH, and lipopolysaccharide (LPS) were purchased from Sigma-Aldrich (St. Louis, MO, USA). Dulbecco's modified Eagle's medium (DMEM) and fetal bovine serum (FBS) were obtained from Thermo Fisher Scientific, Inc. (Waltham, MA, USA). Standard monosaccharides including glucose, xylose, rhamnose, arabinose, mannose and galactose were obtained from Sangon Biotech Co., Ltd. (Shanghai, China). Sephadex G-100 was purchased from GE Healthcare Life Sciences (Chalfont, UK).

Incubation and fermentation of T. aurantialba. T. aurantialba was initially cultured on potato dextrose agar (PDA) slant tube medium containing $20 \%$ potato, $2 \%$ glucose and $2 \%$ agar, and then transferred to PDA plates. Following incubation at $28^{\circ} \mathrm{C}$ for 14 days, sections of $T$. aurantialba mycelium from PDA plates were transferred to liquid medium containing $20 \%$ potato, $2 \%$ glucose, $0.3 \% \mathrm{KH}_{2} \mathrm{PO}_{4}, 0.15 \%$ $\mathrm{MgSO}_{4} \cdot 7 \mathrm{H}_{2} \mathrm{O}$ and $0.01-0.02 \mathrm{mg} / \mathrm{ml}$ vitamin B1. Fermentation was performed in a flask shaken at $220 \mathrm{rpm}$ for 14 days at $28^{\circ} \mathrm{C}$.

Preparation and purification of polysaccharides from $T$. aurantialba mycelia. Mycelia were obtained from culture broths using a Buchner funnel and air-dried. Extraction was performed by incubating mycelia with $1.25 \mathrm{~mol} / 1 \mathrm{NaOH}$ solution containing $0.05 \%(\mathrm{w} / \mathrm{v}) \mathrm{NaBH}_{4}$ at room temperature for 4-6 h. Following pumping filtration to remove mycelia fragments, the residues were neutralized with $2 \mathrm{~mol} / \mathrm{l}$ acetic acid and centrifuged at $4,000 \times \mathrm{g}$ for $30 \mathrm{~min}$ at room temperature. Supernatants were collected, concentrated to $1 / 5$ of the original volume and precipitated with four volumes of $95 \%(\mathrm{v} / \mathrm{v})$ ethanol solution. The precipitate was collected and washed with deionized water. Subsequently, the solution was deproteinated by mixing with an equal volume of Sevage reagent (chloroform:n-butanol [4:1 (v/v)]) and centrifuging at 4,000 x $g$ for $30 \mathrm{~min}$ at $4^{\circ} \mathrm{C}$. This solution was then precipitated with four volumes of $95 \%(\mathrm{v} / \mathrm{v})$ ethanol solution. The precipitate was freeze-dried and designated as CMCP.

CMCP was dissolved in deionized water $(5 \mathrm{mg} / \mathrm{ml})$ and purified by gel permeation chromatography using a Sephadex $\mathrm{G}-100$ column $(1 \times 30 \mathrm{~cm})$. Aliquots $(1 \mathrm{ml})$ were applied to the column, which was eluted with $0.1 \mathrm{~mol} / 1 \mathrm{NaCl}$ at a flow rate of $0.75 \mathrm{ml} / \mathrm{min}$, with each tube collecting $0.75 \mathrm{ml}$ effluent. The polysaccharide content of effluent was determined by the phenol-sulfuric acid method (13). The elution curve was obtained indirectly using the number of collecting tubes as the abscissa and the absorbance of the effluent-phenol-sulfuric acid reaction system as the ordinate (Fig. 1). Collected liquid from the single peak was merged and dialyzed against deionized water in a cellulose dialysis tube. The solution was freeze-dried in a vacuum to obtain the purified polysaccharide (MCP).
Chemical analysis of polysaccharides

Determination of total sugar, uronic acid and protein content. The total sugar content of CMCP and MCP was analyzed using the phenol-sulfuric acid method (13), while the uronic acid and protein content were determined by the carbazole-sulfuric acid and Coomassie brilliant blue methods (14), respectively.

Monosaccharide analysis of MCP. MCP (20 mg) was hydrolyzed with $1 \mathrm{M} \mathrm{H}_{2} \mathrm{SO}_{4}$ at $100^{\circ} \mathrm{C}$ for $5 \mathrm{~h}$ in a thermostatic water bath (HH-8; Jintan Xinxin Experimental Instrument Co., Ltd., Changzhou, China). The hydrolysate was neutralized with excess $\mathrm{BaCO}_{3}$. The obtained solution was centrifuged at $2,600 \times g$ for $15 \mathrm{~min}$ at room temperature. Subsequently, the free monosaccharide was obtained from the supernatant by drying in a vacuum oven at $45^{\circ} \mathrm{C}$. The dried monosaccharide $(10 \mathrm{mg})$ was added to hydroxylamine hydrochloride $(10 \mathrm{mg})$, inositol $(2 \mathrm{mg})$ and pyridine $(0.5 \mathrm{ml})$ and incubated at $90^{\circ} \mathrm{C}$ for $30 \mathrm{~min}$. The solution was then mixed with acetic anhydride $(0.5 \mathrm{ml})$ in a constant temperature water bath at $90^{\circ} \mathrm{C}$ for $30 \mathrm{~min}$. The monosaccharide composition was determined by gas chromatography analysis using the methods described previously (15).

Determination of molecular weight of MCP. The molecular weight (MW) of samples was determined by gel permeation chromatography (GPC) using a method described in our previous study (16). In brief, the samples were separated on an Agilent 1200 Liquid Chromatography system equipped with a G1310A pump, a PL aquagel-OH column $(7.5 \times 300 \mathrm{~mm}$; Agilent Technologies, Inc., Santa Clara, CA, USA.) and a differential refractive index detector (RID; G1362A). The column and RID detector temperature was maintained at $25^{\circ} \mathrm{C}$, the flow rate of the mobile phase $\left(0.1 \mathrm{M} \mathrm{NaNO}_{3}\right)$ was $0.8 \mathrm{ml} / \mathrm{min}$, and all solutions were filtered with $0.45 \mu \mathrm{m}$ syringe filter. The column was calibrated with dextran standards of varying molecular weights $(10,000,41,100,84,400,133,800,275,900$ and 606,200 Da).

Infrared spectroscopy of MCP. Fourier transform infrared (FTIR) spectroscopy of MCP (2 mg) mixed with dry $\mathrm{KBr}$ (200 mg) was performed at room temperature in the $4000 \mathrm{~cm}^{-1}$ to $500 \mathrm{~cm}^{-1}$ region (Thermo Fisher Scientific, Inc.).

\section{Antioxidant activity assay of polysaccharides}

Determination of reducing power. The reducing power of CMCP and MCP was determined according to a previously described method (17) with slight modifications. Briefly, various concentrations of polysaccharides $(50,100,200,400$ or $1,000 \mu \mathrm{g} / \mathrm{ml})$ in $1 \mathrm{ml}$ distilled water were mixed with phosphate buffer [2.5 ml, $2 \mathrm{M}(\mathrm{pH} 6.6)]$ and potassium ferricyanide $\left[\mathrm{K}_{3} \mathrm{Fe}(\mathrm{CN})_{6} ; 0.25 \mathrm{ml}, 1 \%(\mathrm{w} / \mathrm{v})\right]$. Following an incubation at $50^{\circ} \mathrm{C}$ for $20 \mathrm{~min}, 0.5 \mathrm{ml}$ trichloroacetic acid $[10 \%(\mathrm{w} / \mathrm{v})]$ was added to the mixture to terminate the reaction. The solution was centrifuged at $3,000 \times \mathrm{g}$ for $10 \mathrm{~min}$ at room temperature. An aliquot of $1.5 \mathrm{ml}$ supernatant was collected, mixed with $0.1 \mathrm{ml} \mathrm{FeCl} l_{3}[0.1 \%$, (w/v)] and $3 \mathrm{ml}$ deionized water, and incubated at room temperature for $5 \mathrm{~min}$. The absorbance of polysaccharides was measured at a wavelength of $700 \mathrm{~nm}$ using an ultraviolet visible spectrophotometer (UVmini-1240; Shimadzu International Trading Co., Ltd, Shanghai, China). 


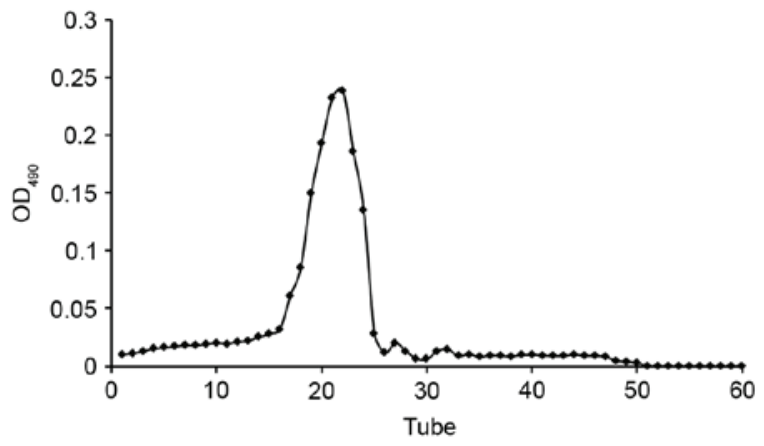

Figure 1. Elution curve of mycelia polysaccharide. The elution curve was obtained indirectly with the abscissa representing the number of collecting tubes and the ordinate representing the absorbance of the effluent-phenol-sulfuric acid reaction system. Liquid collected from the single peak was merged and dialyzed against deionized water in a cellulose dialysis tube. The solution was freeze-dried in a vacuum to obtain the purified mycelium polysaccharide. OD, optical density.

DPPH scavenging activity. DPPH radical scavenging activity was determined according to a previously described method (18) with slight modifications. A total of $1 \mathrm{ml}$ polysaccharide $(50,100,200,400$ or $1,000 \mu \mathrm{g} / \mathrm{ml})$ was added to a $0.004 \%$ ethanol solution of DPPH $(3.0 \mathrm{ml})$, and incubated at room temperature for $30 \mathrm{~min}$ in the dark. In the control group, 95\% ethanol replaced the DPPH solution, while distilled water was used as the blank. The absorbance of each reaction mixture was measured at a wavelength of $517 \mathrm{~nm}$ using an ultraviolet visible spectrophotometer (Shimadzu International Trading Co., Ltd.). The DPPH scavenging activity was calculated as follows:

$$
\begin{gathered}
\text { Scavenging ability }(\%)=\left[1-\left(\mathrm{A}_{\text {sample517 }}-\mathrm{A}_{\text {control517 }}\right) / \mathrm{A}_{\text {blank517 }}\right] \\
\text { X100 }
\end{gathered}
$$

Hydroxyl radical scavenging activity. The hydroxyl radical scavenging activity of the polysaccharide was determined using Fenton's reaction, as previously described (19). The reaction mixture consisted of $1 \mathrm{ml}$ polysaccharide $(50,100$, $200,400$ or $1,000 \mathrm{ug} / \mathrm{ml}), 0.9 \mathrm{ml} \mathrm{EDTA}-\mathrm{FeSO}_{4}(0.15 \mathrm{mM})$, $0.5 \mathrm{ml} \mathrm{H} \mathrm{O}_{2}(8.8 \mathrm{mM})$ and $0.5 \mathrm{ml}$ salicylic acid $(9 \mathrm{mM})$. In the control group, water replaced the sample and sodium phosphate replaced the $\mathrm{H}_{2} \mathrm{O}_{2}$, while water was used as the blank. Following incubation at $37^{\circ} \mathrm{C}$ for $60 \mathrm{~min}$, the absorbance of samples was measured at a wavelength of $510 \mathrm{~nm}$. The hydroxyl radical scavenging activity was calculated as follows:

$$
\begin{gathered}
\text { Scavenging ability }(\%)=\left[1-\left(\mathrm{A}_{\text {sample510 }}-\mathrm{A}_{\text {control510 }}\right) / \mathrm{A}_{\text {blank510 }}\right] \\
\text { X100 }
\end{gathered}
$$

RAW264.7 cell culture. RAW264.7 cells were cultured in DMEM supplemented with $10 \%$ FBS, in a water-jacketed incubator (Thermo Fisher Scientific, Inc.) at $37^{\circ} \mathrm{C}$ with $5 \%$ $\mathrm{CO}_{2}$ in a humidified atmosphere. The medium was replaced every day, and the cells were passaged every second day. Cells were used in subsequent experiments when $80 \%$ confluency was reached.

MTT assay. An MTT assay was performed as previously described (20) to determine the effect of polysaccharides on the proliferation of RAW264.7 cells. Briefly, RAW264.7 cells, at a density of $5 \times 10^{4} / \mathrm{ml}$, were seeded in 96-well plates and incubated with $100 \mu$ l test samples at various concentrations $(50,100$ or $200 \mu \mathrm{g} / \mathrm{ml})$ for $48 \mathrm{~h}$. Cells treated with LPS $(1 \mu \mathrm{g} / \mathrm{ml})$ served as a positive control, while cells treated with medium alone were used as a negative control. Subsequently, $10 \mu \mathrm{l}$ of MTT $(5 \mathrm{mg} / \mathrm{ml})$ was added to each well and incubated for a further $4 \mathrm{~h}$ at $37^{\circ} \mathrm{C}$. The plates were centrifuged at $1,000 \times \mathrm{g}$ for $5 \mathrm{~min}$ at room temperature. Following removal of the supernatant, $100 \mu \mathrm{l}$ of DMSO was added to each well. Plates were agitated for $10 \mathrm{~min}$ to dissolve the produced formazan crystals, and the optical densities were measured at a wavelength of $570 \mathrm{~nm}$ using a microplate reader.

Influence of polysaccharide on NO secretion of RAW264.7. Nitrite accumulation served as a marker of NO production in culture medium, and was measured using the Griess reaction (21). RAW264.7 cells were seeded in 96-well plates at a density of $5 \times 10^{4}$ cells/well and incubated at $37^{\circ} \mathrm{C}$ and $5 \% \mathrm{CO}_{2}$ in a humidified atmosphere for $6 \mathrm{~h}$. Cells were treated with polysaccharides $(50,100$ or $200 \mu \mathrm{g} / \mathrm{ml})$, LPS (positive control) or culture media alone (negative control). Nitrite production was determined using a Griess kit (Beyotime Institute of Biotechnology, Shanghai, China) according to the manufacturer's instructions.

Influence of polysaccharide on cytokine secretion by RAW264.7 cells. The production of IL-1, IL- 6 and TNF- $\alpha$ by RAW264.7 cells was detected using enzyme-linked immunosorbent assay kits (cat. nos. MLB00C, M6000B and MTA00B, respectively; R\&D Systems, Inc., Minneapolis, MN, USA) according to the manufacturer's instructions. Cells $\left(5 \times 10^{4}\right.$ cells/well) were seeded in 96-well plates and treated as for the experimental, positive control and negative control groups described above.

Statistical analysis. Data analyses were performed using SPSS software version 19.0 (IBM SPSS, Armonk, NY, USA). Data are presented as the mean \pm standard deviation. The results were analyzed using one-way analysis of variance followed by the least significant difference test. $\mathrm{P}<0.05$ was considered to indicate a statistically significant difference.

\section{Results}

Fermentation of T. aurantialba was successful. Fig. 2 presents the growth curve of T. aurantialba in culture plates (Fig. 2A) and the growth curve of mycelium in shake-flasks (Fig. 2B). The colony of T. aurantialba was roundish, white and opaque with a matte surface. The diameter of the colony in the plate increased gradually over time, and covered the plate by day 14 . In addition, the biomass of mycelium in shake-flasks increased over time, reaching $0.34 \mathrm{~g} / 50 \mathrm{ml}$ on the day 10 , following which the biomass plateaued. Mycelium consisted of golden yellow spherical particles, with good dispersion in the liquid medium. The fermentation broth was clear, with a color that darkened gradually over time.

Mycelia polysaccharide were isolated and the composition analyzed. The yield of CMCP from T. aurantialba was $1.53 \%$, 
Table I. Molecular weight of MCP.

\section{Molecular weight \\ $\left(\mathrm{x} 10^{4} \mathrm{~g} / \mathrm{mol}\right)$}

\begin{tabular}{lccc}
\cline { 2 - 3 } Sample & $M_{w} / M_{n}$ & $M_{w}$ & $M_{n}$ \\
\hline MCP & 4.30 & 2.95 & 1.46 \\
\hline
\end{tabular}

MCP, purified mycelium polysaccharides; Mw, weight-average molecular weight; $\mathrm{Mn}$, number-average molecular weight.
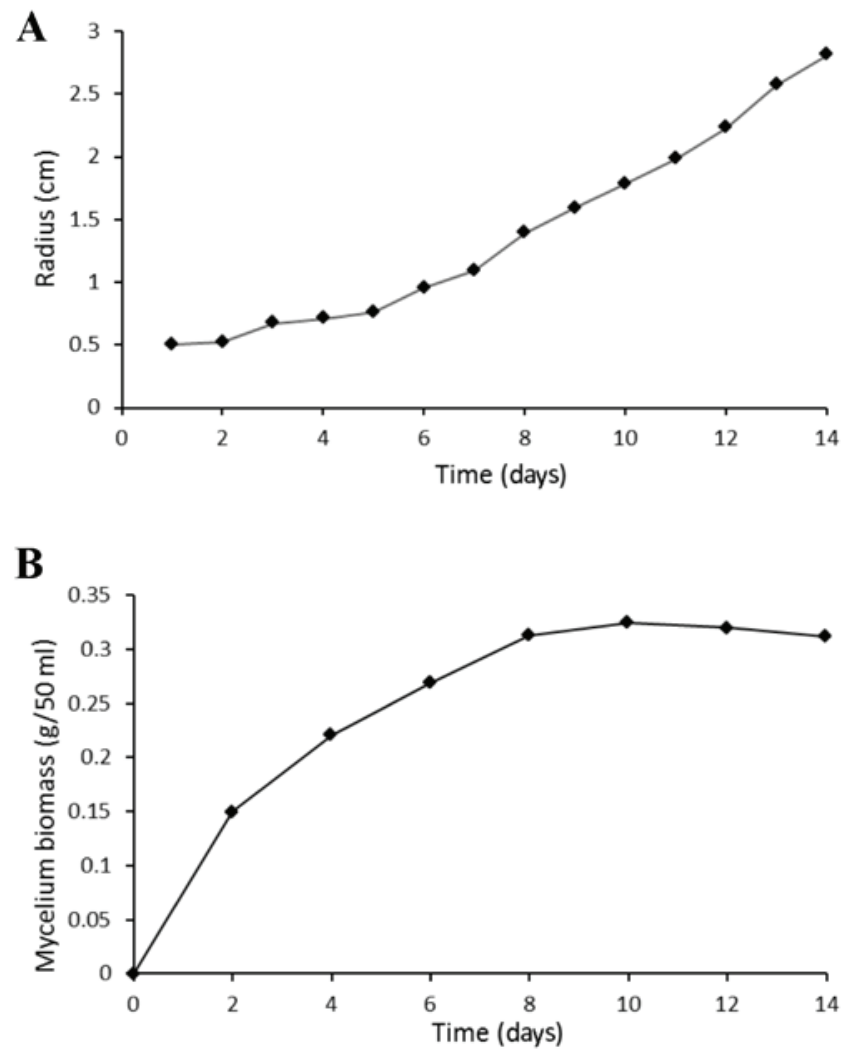

Figure 2. (A) Growth curve of T. aurantialba in culture plates. The radius of the colony in the plate increased gradually over time, and covered the plate by day 14. (B) Growth curve of mycelium in shake-flask liquid cultures. The biomass of mycelium in shake-flasks increased over time, reaching $0.34 \mathrm{~g} / 50 \mathrm{ml}$ on day 10 , at which point the biomass plateaued.

the total carbohydrate content was $11.92 \%$ and the residual protein content was $21.7 \%$. The total carbohydrate and residual protein content of MCP were 86.59 and 3.5\%, respectively, following deproteinization using the Sevage method and purification on a Sephadex G-100 column. The uronic acid content was $16.4 \%$ and the molecular weight of MCP as determined by GPC was $4.3 \times 10^{4} \mathrm{~g} / \mathrm{mol}$ (Table I).

Table II presents the monosaccharide composition and content of MCP. MCP was comprised of D-glucose, D-galactose and D-mannose, with traces of D- rhamnose, D-arabinose and D-xylose.

The FTIR spectrum of MCP is presented in Fig. 3. The FTIR spectrum revealed a strong broad absorption peak at $3,425 \mathrm{~cm}^{-1}$ due to the $\mathrm{O}-\mathrm{H}$ stretching vibration of the
Table II. Monosaccharide composition of purified mycelium polysaccharides.

Monosaccharide composition

Content $(\%)$

\begin{tabular}{lr}
\hline Rhamnose & 1.31 \\
Arabinose & 0.74 \\
Xylose & 1.36 \\
Mannose & 4.53 \\
Glucose & 82.17 \\
Galactose & 9.89
\end{tabular}

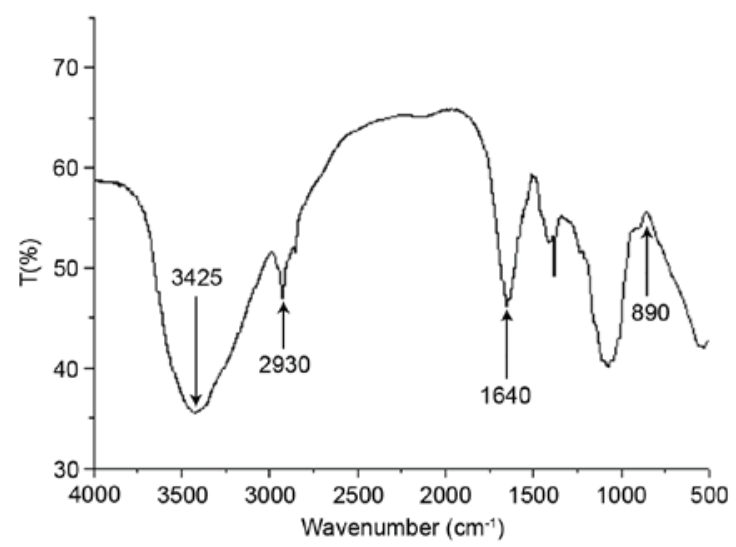

Figure 3. Fourier transform infrared spectrum of purified mycelium polysaccharides. The broad absorption peak was observed at $3,425 \mathrm{~cm}^{-1}$ due to the $\mathrm{O}-\mathrm{H}$ bond stretching vibration of the polysaccharide. A peak at $2,930 \mathrm{~cm}^{-1}$ was observed due to the $\mathrm{C}-\mathrm{H}$ bond stretching vibration, and the absorption peak at $1,640 \mathrm{~cm}^{-1}$ was characteristic of the $\mathrm{C}=\mathrm{O}$ bond stretching vibration. No notable $\mathrm{C}=\mathrm{O}$ vibration was observed at $3,000-2,500 \mathrm{~cm}^{-1}$, suggesting that the uronic acid content was low. In addition, an absorption peak at $890 \mathrm{~cm}^{-1}$ indicated that the polysaccharide was connected by a $\beta$-glycosidic bond. $\mathrm{T}$, infrared transmittance.

polysaccharide and a peak at $2,930 \mathrm{~cm}^{-1}$ due to the $\mathrm{C}-\mathrm{H}$ stretching vibration. FTIR spectrum of MCP exhibited an absorption peak at $1,640 \mathrm{~cm}^{-1}$, which was a characteristic of the $\mathrm{C}=\mathrm{O}$ stretching vibration. No notable $\mathrm{C}=\mathrm{O}$ vibration was observed at $3,000-2,500 \mathrm{~cm}^{-1}$, suggesting that the content of uronic acid was low. In addition, an absorption peak at $890 \mathrm{~cm}^{-1}$ indicated that the polysaccharide was connected by a $\beta$-glycosidic bond.

\section{Antioxidant activity of $C M C P$ and $M C P$}

The reducing power of $M C P$ was greater than $C M C P$. As presented in Fig. 4A, the reducing power of $\mathrm{CMCP}$ and $\mathrm{MCP}$ was increased in a dose-dependent manner in the range of $50-1,000 \mu \mathrm{g} / \mathrm{ml}$. The reducing power of MCP was 1.26 -fold greater than that of CMCP. At $1,000 \mu \mathrm{g} / \mathrm{ml}$, the maximum reducing power of $\mathrm{CMCP}$ and $\mathrm{MCP}$ was 0.18 and 0.23 , respectively.

DPPH scavenging activity was increased with MCP treatment compared to CMCP. As presented in Fig. 4B, a rapid increase was observed in the DPPH scavenging activity with increasing MCP concentrations (50-400 $\mu \mathrm{g} / \mathrm{ml})$, while this rapid increase occurred in the DPPH scavenging activity of CMCP between 

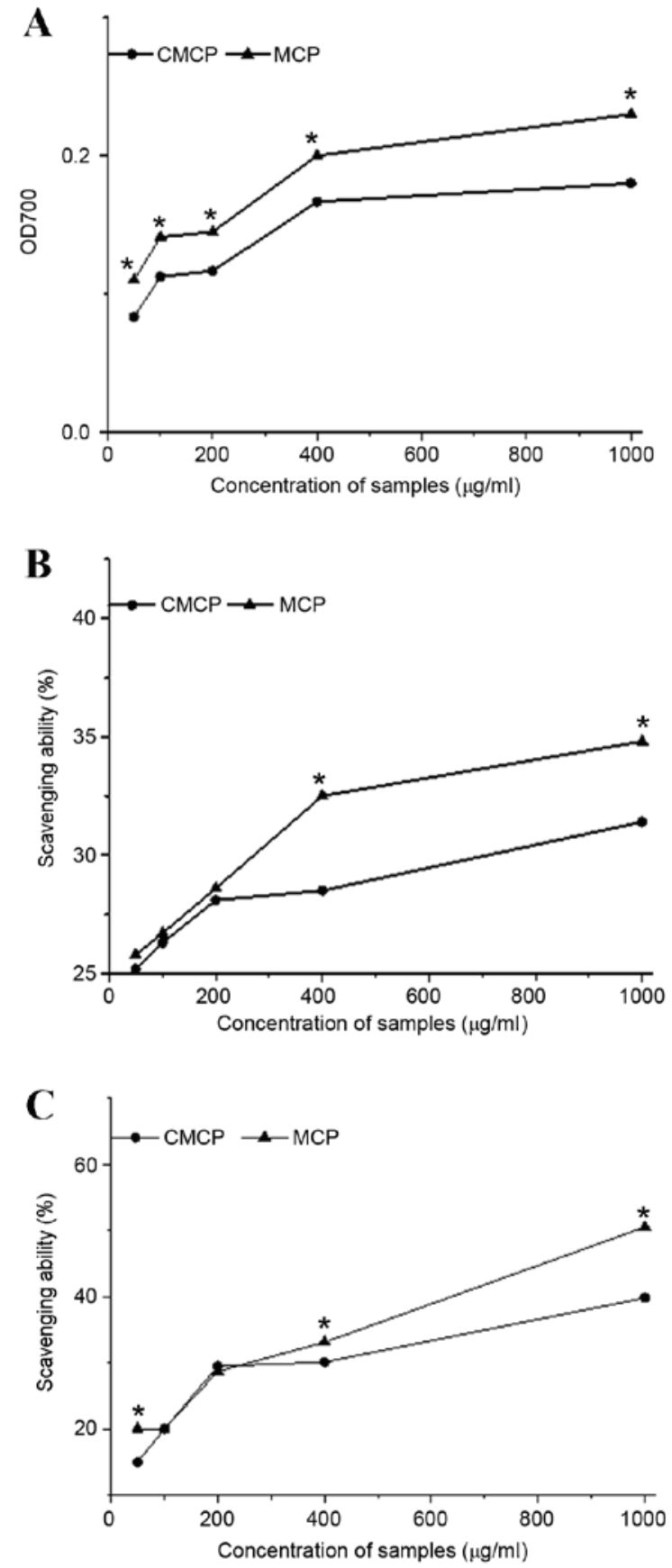

Figure 4. Antioxidant activity of polysaccharide extracted from T. aurantialba mycelia. (A) Reducing power, (B) scavenging activity to DPPH and (C) scavenging activity to the hydroxyl of MCP and CMCP were measured. MCP exerted a greater reducing power compared with $\mathrm{CMCP}$ in the concentration range evaluated. Furthermore, MCP exhibited superior scavenging activities of DPPH and hydroxyl radicals compared with CMCP. ${ }^{\prime} \mathrm{P}<0.05$ vs. CMCP at the same concentration. DPPH, 2,2-diphenyl-1-picrylhydrazyl; MCP, purified mycelium polysaccharides; CMCP, crude mycelium polysaccharides; OD, optical density.

50 and $200 \mu \mathrm{g} / \mathrm{ml}$. At a concentration of $1,000 \mu \mathrm{g} / \mathrm{ml}$, the scavenging effect of MCP and CMCP reached maximums of 35.02 and $31.84 \%$, respectively. In addition, no significant difference was observed between MCP and CMCP at concentrations of $50-200 \mu \mathrm{g} / \mathrm{ml}$. The DPPH scavenging activity of MCP was significantly greater than that of $\mathrm{CMCP}$ at concentrations $>200 \mu \mathrm{g} / \mathrm{ml}(400 \mu \mathrm{g} / \mathrm{ml}, \mathrm{P}=0.002 ; 1,000 \mu \mathrm{g} / \mathrm{ml}, \mathrm{P}=0.008$; Fig. 4B).

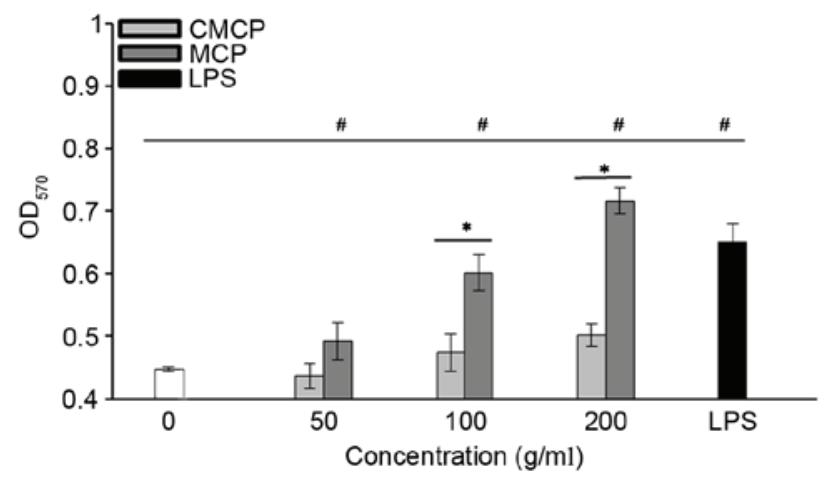

Figure 5. Polysaccharides from T. aurantialba mycelia induced the proliferation of RAW264.7 cells. MCP stimulated the proliferation of RAW264.7 cells at concentrations of 50-200 $\mu \mathrm{g} / \mathrm{ml}$ in a dose-dependent manner. At $200 \mu \mathrm{g} / \mathrm{ml}$, MCP was more effective than the positive control. However, CMCP did not promote the proliferation of RAW264.7 cells concentrations ranging from 50 to $200 \mu \mathrm{g} / \mathrm{ml}$. Data are presented as the mean \pm standard deviation $(\mathrm{n}=3)$. ${ }^{*} \mathrm{P}<0.05$ vs. $\mathrm{CMCP}$ at the same concentration; ${ }^{\#} \mathrm{P}<0.05$ vs. negative control. MCP, purified mycelium polysaccharides; CMCP, crude mycelium polysaccharides; LPS, lipopolysaccharide; OD, optical density.

Scavenging activity of hydroxyl radicals was increased with $M C P$ compared with CMCP. The hydroxyl radical scavenging activity of MCP and CMCP is presented in Fig. 4C. The scavenging activity of the hydroxyl radicals increased with increasing concentrations of MCP and $\mathrm{CMCP}$, with the greatest scavenging ability at $1,000 \mu \mathrm{g} / \mathrm{ml}$. The scavenging ability of MCP was significantly greater than that of CMCP at 50 and $400-1,000 \mu \mathrm{g} / \mathrm{ml}(50 \mu \mathrm{g} / \mathrm{ml}, \mathrm{P}=0.003 ; 400 \mu \mathrm{g} / \mathrm{ml}$, $\mathrm{P}=0.006 ; 1,000 \mu \mathrm{g} / \mathrm{ml}, \mathrm{P}<0.001)$. No statistical difference was observed at concentrations of $100-200 \mu \mathrm{g} / \mathrm{ml}$.

The difference between MCP and CMCP antioxidant activities may be due to differences in total carbohydrate content.

\section{Immunostimulatory activity of $C M C P$ and $M C P$}

MCP induced proliferation of RAW264.7 cells. Fig. 5 presents the effects of polysaccharides on the proliferation of RAW264.7 cells. MCP stimulated the proliferation of RAW264.7 cells at concentrations of 50-200 $\mu \mathrm{g} / \mathrm{ml}(\mathrm{P}<0.05)$, in a dose-dependent manner. At $200 \mu \mathrm{g} / \mathrm{ml}$, MCP was more effective than the positive control. However, no stimulative effects of $\mathrm{CMCP}$ on RAW264.7 cell proliferation were observed at concentrations of $50-200 \mu \mathrm{g} / \mathrm{ml}(\mathrm{P}>0.05)$. These results indicate that MCP, but not CMCP, significantly induced proliferation of RAW264.7 cells.

High concentration of MCP and CMCP increased NO secretion by RAW264.7 cells. The effects of CMCP and MCP on NO production by RAW264.7 cells were evaluated by measuring the release of nitrite. As presented in Fig. 6, no significant increase in NO production was observed with $50 \mu \mathrm{g} / \mathrm{ml} \mathrm{MCP}$ or $\mathrm{CMCP}(\mathrm{P}>0.05)$. Concentrations of $\mathrm{MCP}>100 \mu \mathrm{g} / \mathrm{ml}$ significantly increased $\mathrm{NO}$ production compared with the negative control $(\mathrm{P}<0.05)$. Increased NO production was observed in the CMCP-treated cells only at a concentration of $200 \mu \mathrm{g} / \mathrm{ml}$, and remained significantly reduced compared with MCP at the same concentration $(\mathrm{P}<0.05)$.

MCP greatly increased cytokine secretion by RAW264.7 cells. The effects of MCP and CMCP on the production of TNF- $\alpha$ 


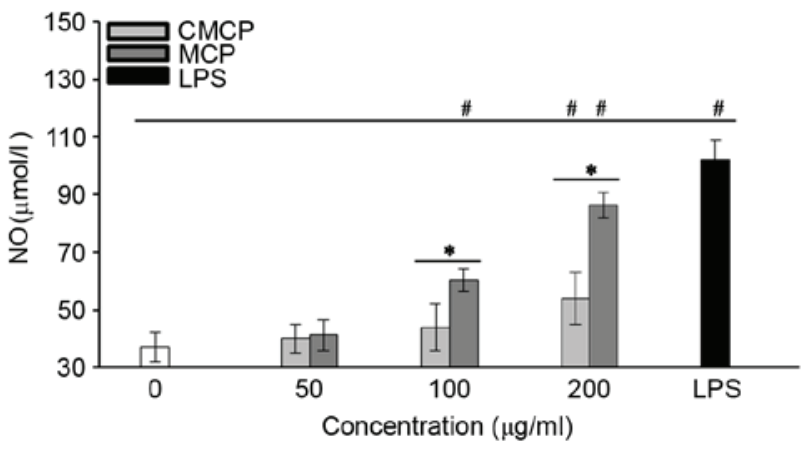

Figure 6. Effects of polysaccharides from T. aurantialba mycelia on NO production in RAW264.7 cells. No significant increase in NO production was observed with $50 \mu \mathrm{g} / \mathrm{ml}$ MCP or CMCP. Concentrations of MCP $>100 \mu \mathrm{g} / \mathrm{ml}$ significantly increased NO production when compared with the negative control. Increased NO production was observed in the CMCP-treated cells only at a concentration of $200 \mu \mathrm{g} / \mathrm{ml}$, and remained significantly reduced compared with MCP at the same concentration. Data are presented as the mean \pm standard deviation $(\mathrm{n}=3)$. ${ }^{*} \mathrm{P}<0.05$ vs. $\mathrm{CMCP}$ at the same concentration; " $\mathrm{P}<0.05$ vs. negative control. NO, nitric oxide; MCP, purified mycelium polysaccharides; CMCP, crude mycelium polysaccharides; LPS, lipopolysaccharide.

(Fig. 7A), IL-1 (Fig. 7B) and IL-6 (Fig. 7C) by RAW264.7 cells were investigated. Cytokine levels were significantly upregulated in cells treated with 100 and $200 \mu \mathrm{g} / \mathrm{ml}$ MCP compared with those in the negative control group $(\mathrm{P}<0.05)$. CMCP did not induce production of IL-1 or -6 at the concentrations tested $(\mathrm{P}>0.05)$; however, it did stimulate TNF- $\alpha$ secretion at $200 \mu \mathrm{g} / \mathrm{ml}(\mathrm{P}<0.05)$, indicating that $\mathrm{CMCP}$ has a reduced potency compared with MCP. These results indicate that the effects of polysaccharides on macrophage activation may be associated with the total carbohydrate content in MCP and CMCP.

\section{Discussion}

The composition and structure of polysaccharides from T. aurantialba have been reported to be closely associated with their biological properties. Biological activities may be affected by numerous factors, including diverse monosaccharide composition, glycosidic bond type and molecular weight, as well as molecular conformation. Kiho et al (22) reported that the polysaccharide TAP from T. aurantialba comprised mannose, xylose, glucuronic acid and glucose, and exhibited potent hypoglycemic activity, which was the result of non-reducing terminal $\alpha$-D-mannopyranosyl residues. Furthermore, the specific structure of TAP contributed to its effect on a key hepatic enzyme and plasma cholesterol levels in healthy and diabetic mice $(22,23)$. In the present study, chemical analysis indicated that MCP obtained by fermentation was composed primarily of D-glucose, D-galactose and $\mathrm{D}$-mannose, and was connected by a $\beta$-glycosidic bond.

Accumulating evidence indicates antioxidant properties for numerous edible mushrooms, including $D$. indusiata, T. giganteum and P. cystidiosus $(24,25)$. Kasuga et al $(26)$ demonstrated that methanolic extracts from ear mushrooms exhibited marked reducing power in chelating ferrous ions and scavenging of DPPH and hydroxyl radicals. In addition, it has been reported that various extracts from H. marmoreus exerted
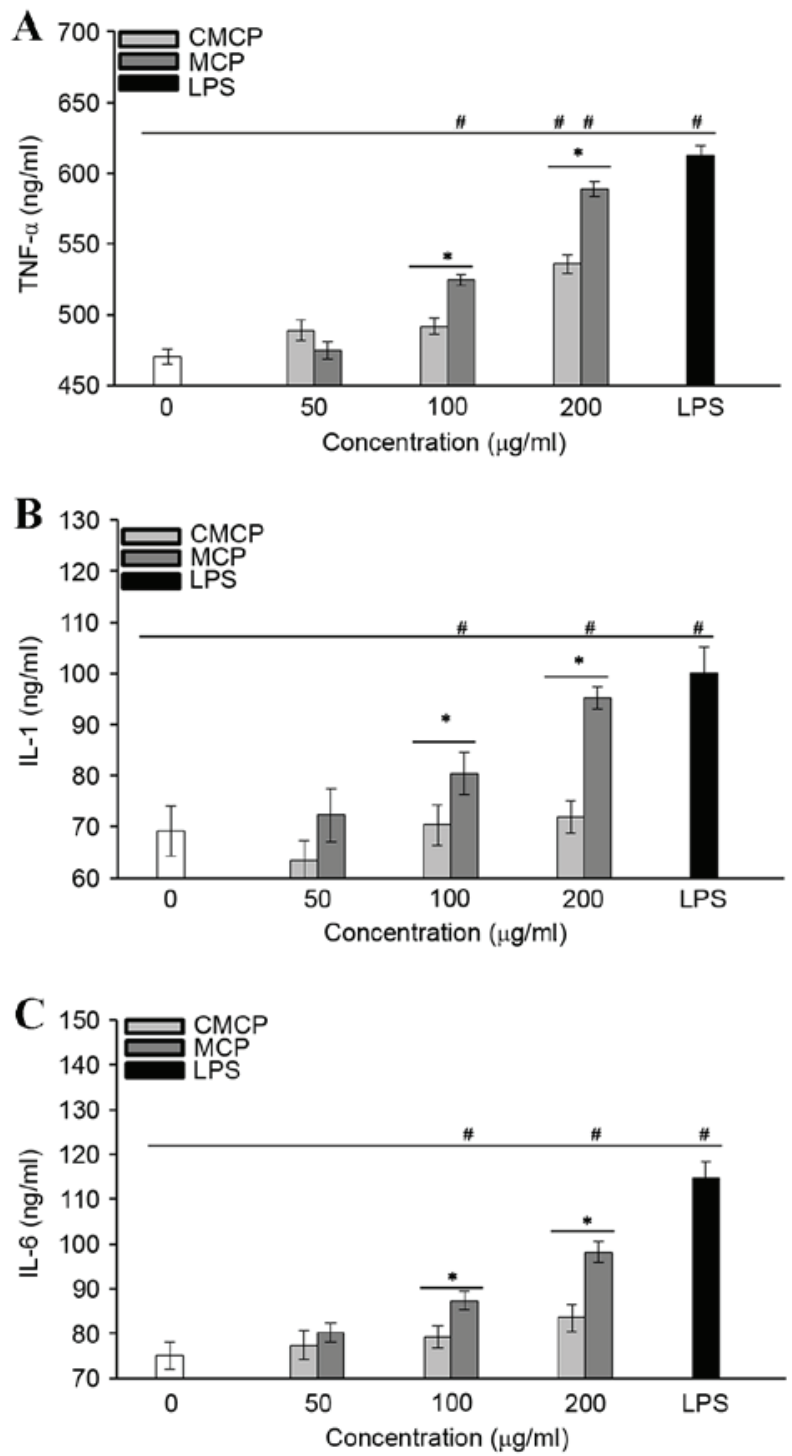

Figure 7. Effects of polysaccharides from T. aurantialba mycelia on the production of various cytokines in RAW264.7 cells. (A) TNF- $\alpha$ production (B) IL-1 production and (C) IL-6 production were measured by enzyme-linked immunosorbent assay. Each experiment was repeated in triplicate. Cytokine levels were significantly upregulated in cells treated with 100 and $200 \mu \mathrm{g} / \mathrm{ml}$ MCP compared with those in the negative control group. CMCP did not induce the production of IL-1 or IL- 6 at all concentrations tested. However, CMCP stimulated TNF- $\alpha$ secretion at $200 \mu \mathrm{g} / \mathrm{ml}$, which indicates that $\mathrm{CMCP}$ has a reduced potency compared with MCP. Data are presented as the mean \pm standard deviation $(\mathrm{n}=3)$. ${ }^{*} \mathrm{P}<0.05$ vs. $\mathrm{CMCP}$ at the same concentration; ${ }^{~} \mathrm{P}<0.05$ vs. negative control. MCP, purified mycelium polysaccharides; CMCP, crude mycelium polysaccharides; LPS, lipopolysaccharide; TNF- $\alpha$, tumor necrosis factor- $\alpha$; IL, interleukin.

antioxidant activities of 38.6-65.2\% and a reducing power of 0.99 at a concentration of $5 \mathrm{mg} / \mathrm{ml}$ (27). Du et al (28) revealed that the chloroform extract derived from T. aurantialba fruiting bodies exhibited satisfactory antioxidant activity, and all chloroform, ethyl acetate and ethanol extracts exerted a greater scavenging activity on hydroxyl compared with superoxide anion radicals. However, less is known about the antioxidant activity of polysaccharides from $T$. aurantialba mycelium. In the present study, MCP obtained following fermentation exerted a greater reducing power compared with $\mathrm{CMCP}$ in the concentration range evaluated. Furthermore, MCP exhibited 
superior scavenging activities of DPPH and hydroxyl radicals compared with CMCP. These results indicate that the difference in antioxidant activities between MCP and CMCP may be associated with the total carbohydrate content.

Immunomodulatory effects have been associated with polysaccharides (29). The mechanism underlying immunoregulation primarily involves the induction of proliferation of various immune cells, including macrophages, lymphocytes and natural killer cells, and the stimulation of inflammatory mediator production by these cells (30). Therefore, proliferation assays are an appropriate method to rapidly screen the immunostimulatory activity of polysaccharides. Numerous reports have demonstrated the immunostimulatory activity of polysaccharides isolated from $T$. aurantialba. Lee et al (6) revealed that methanol soluble substances extracted from the fruiting body of $T$. aurantialba improved the activity of B lymphocytes, in which the alkaline phosphatase activity was increased 1.16-fold at the concentration of $200 \mu \mathrm{g} / \mathrm{ml}$. Du et al (31) indicated that the acidic polysaccharide TAPA1 from $T$. aurantialba markedly stimulated the proliferation of murine lymphocytes in vitro in a dose-dependent manner. In the present study, 50-200 $\mu \mathrm{g} / \mathrm{ml}$ MCP significantly increased proliferation of RAW264.7 macrophages. In addition, MCP exhibited a greater effect than LPS, while only $200 \mu \mathrm{g} / \mathrm{ml}$ CMCP promoted RAW264.7 cell proliferation.

Macrophages are important components of the immune system, which are crucial in host defense and acute inflammatory responses (32). NO, which is produced by macrophages, is an inorganic molecule that is critical in injury, inflammation and defense. Previous studies have indicated that polysaccharides stimulate NO production by macrophages, accompanied an improvement in immune function $(33,34)$. Du et al $(35)$ suggested that all polysaccharides (TAPA1, TAPA1-deac and TAPA1-ac) isolated from $T$. aurantialba fruiting bodies stimulated RAW264.7 macrophages to produce NO. In the present study, a significant increase in NO production was observed following treatment with $>100 \mu \mathrm{g} / \mathrm{ml} \mathrm{MCP}$, compared with the negative control group $(\mathrm{P}<0.05)$. CMCP promoted $\mathrm{NO}$ production at the concentration of $200 \mu \mathrm{g} / \mathrm{ml}$; however, this remained significantly reduced compared with MCP.

Following stimulation by various external factors, activated macrophages generate a variety of other mediators responsible for numerous homeostatic, immunologic and inflammatory processes, including IL-1, IL-6 and TNF- $\alpha$. Therefore, cytokine production may be reflective of the inflammatory process and may provide a method to assess the effects of polysaccharide on macrophage activation. In the present study, 100 and $200 \mu \mathrm{g} / \mathrm{ml} \mathrm{MCP} \mathrm{significantly}$ upregulated the levels of IL-1, IL- 6 and TNF- $\alpha$ produced by RAW264.7 macrophages, compared with the negative control group $(\mathrm{P}<0.05)$. CMCP induced only $\mathrm{TNF}-\alpha$ production at a concentration of $200 \mu \mathrm{g} / \mathrm{ml}$, with a reduced potency compared with MCP. Taken together, these results suggest that the total carbohydrate content in MCP and CMCP may contribute to differences in immunostimulatory activities.

In conclusion, CMCP was extracted from T. aurantialba mycelia following liquid fermentation. Purification by gel chromatography produced purified polysaccharide MCP. Compared with CMCP, MCP demonstrated significantly increased antioxidant and immunostimulatory activities.
Due to the large difference in total carbohydrate content of MCP and CMCP, the findings of the present study suggest that increased total carbohydrate content may contribute to the increase in antioxidant and immunostimulatory activities. However, further studies are required to identify the mechanisms underlying the antioxidant and immunostimulatory activities of MCP, and to investigate the biological properties of MCP in vivo, to validate its potential clinical applications.

\section{Acknowledgements}

The present study was supported by the Research Fund for the Doctoral Program of Higher Education of China (grant no. 20110093110008) and the College Students' Innovative Training Program of Jiangnan University (grant no. 2015324Y).

\section{References}

1. Bandoni RJ and Boekhout T: Tremelloid genera with yeast phases Fibulobasidium Bandoni, Holtermannia Saccardo \& Traverso, Sirobasidium de Lagerheim \& Patouillard, Tremella Persoon, Trimorphomyces Bandoni \& Oberwinkler. In: The Yeasts: A Taxonomic Study. Kurtzman CP and Fell JW (eds). 4th edition. Elsevier B.V., Amsterdam, pp705-717, 1998.

2. Zhang Z, Li Y and Zhang K: Application of statistical analysis for the optimization of mycelia and polysaccharide production by Tremella aurantialba. Food Technol Biotechnol 45: 45-50, 2007.

3. Zhang ZC, Lian B, Huang DM and Cui FJ: Compare activities on regulating lipid-metabolism and reducing oxidative stress of diabetic rats of Tremella aurantialba broth's extract (TBE) with its mycelia polysaccharides (TMP). J Food Sci 74: H15-H21, 2009.

4. Ding Z, Li J, Liu J, Lu Y, Wang C and Zheng Q: Tremellin, a novel symmetrical compound, from the basidiomycete Tremella aurantialba. Helv Chim Acta 85: 882-884, 2002.

5. Kiho T, Kochi M, Usui S, Hirano K, Aizawa K and Inakuma T: Antidiabetic effect of an acidic polysaccharide (TAP) from Tremella aurantia and its degradation product (TAP-H). Biol Pharm Bull 24: 1400-1403, 2001.

6. Lee GW, Kim HY, Hur H, Lee MW, Shim MJ, Lee UY and Lee TS: Antitumor and immuno-modulatory effect of crude polysaccharides from fruiting body of Tremella aurantialba against mouse sarcoma 180. Korean J Mycol 36: 66-74, 2008

7. Wang H, Qu W, Chu S, Li M and Tian C: Studies on the preventive and therapeutic effects of the polysaccharide of Tremella aurantialba mycelia on diet-induced hyperlipidemia in mice. Acta Nutr Sin 24: 431-432, 2002 (In Chinese).

8. Du XJ,Zhang JS, Yang Y, Tang QJ,Jia W and Pan YJ: Purification, chemical modification and immunostimulating activity of polysaccharides from Tremella aurantialba fruit bodies. J Zhejiang Univ Sci B 11: 437-442, 2010.

9. Kiho T, Kochi M, Usui S, Hirano K, Aizawa K and Inakuma T: Antidiabetic Effect of an Acidic Polysaccharide (TAP) from Tremella aurantia Schw.: Fr.(Heterobasidiomycetes) in Genetically Diabetic KK-Ay Mice. Int J Med Mushrooms 4: 115-123, 2002.

10. Kiho T, Iguchi K, Usui S and Hirano K: Effect of Polysaccharides and $70 \%$ ethanol extracts from medicinal mushrooms on growth of human prostate cancer LNCaP and PC-3 Cells. Int J Med Mushrooms 12: 205-211, 2010.

11. Du X, Zhang Y, Mu H, Lv Z, Yang Y and Zhang J: Structural elucidation and antioxidant activity of a novel polysaccharide (TAPB1) from Tremella aurantialba. Food Hydrocolloid 43: 459-464, 2015.

12. Zhang W, Qu W, Zhang X, Deng Y and Zhu S: The anti-hyperglycemic activity of polysaccharides from Tremella aurantialba mycelium. Acta Nutr Sin 26: 300-303, 2003 (In Chinese).

13. Masuko T, Minami A, Iwasaki N, Majima T, Nishimura S and Lee YC: Carbohydrate analysis by a phenol-sulfuric acid method in microplate format. Anal Biochem 339: 69-72, 2005.

14. Sun Y, Wang H, Guo G, Pu Y and Yan B: The isolation and antioxidant activity of polysaccharides from the marine microalgae Isochrysis galbana. Carbohydr Polym 113: 22-31, 2014. 
15. Chen Y, Xie M, Nie S, Li C and Wang Y: Purification, composition analysis and antioxidant activity of a polysaccharide from the fruiting bodies of Ganoderma atrum. Food Chem 107: 231-241, 2008

16. Deng C, Fu H, Teng L, Hu Z, Xu X, Chen J and Ren T: Anti-tumor activity of the regenerated triple-helical polysaccharide from Dictyophora indusiata. Int J Biol Macromol 61: 453-458, 2013.

17. Oyaizu M: Studies on products of browning reaction-antioxidative activities of products of browning reaction prepared from glucosamine. Jpn J Nutr Diet 44: 307-315, 1986.

18. Rumbaoa R, Cornago D and Geronimo I: Phenolic content and antioxidant capacity of Philippine potato (Solanum tuberosum) tubers. J Food Compos Anal 22: 546-550, 2009.

19. Thomas C, Mackey MM, Diaz AA and Cox DP: Hydroxyl radical is produced via the Fenton reaction in submitochondrial particles under oxidative stress: Implications for diseases associated with iron accumulation. Redox Rep 14: 102-108, 2009

20. Tiffen JC, Bailey CG, Ng C, Rasko JE and Holst J: Luciferase expression and bioluminescence does not affect tumor cell growth in vitro or in vivo. Mol Cancer 9: 299, 2010.

21. JiZ, Tang Q,Zhang J, Yang Y,Jia W and Pan Y: Immunomodulation of RAW264. 7 macrophages by GLIS, a proteopolysaccharide from Ganoderma lucidum. J Ethnopharmacol 112: 445-450, 2007.

22. Kiho T, Kobayashi T, Morimoto H, Usui S, Ukai S, Hirano K, Aizawa $\mathrm{K}$ and Inakuma T: Structural features of an anti-diabetic polysaccharide (TAP) from Tremella aurantia. Chem Pharm Bull (Tokyo) 48: 1793-1795, 2000.

23. Kiho T, Morimoto H, Kobayashi T, Usui S, Ukai S, Aizawa K and Inakuma T: Effect of a polysaccharide (TAP) from the fruiting bodies of Tremella aurantia on glucose metabolism in mouse liver. Biosci Biotechnol Biochem 64: 417-419, 2000.

24. Mau JL, Chao GR and Wu KT: Antioxidant properties of methanolic extracts from several ear mushrooms. J Agri Food Chem 49: 5461-5467, 2001
25. Yang J, Lin $\mathrm{H}$ and Mau J: Antioxidant properties of several commercial mushrooms. Food Chem 77: 229-235, 2002.

26. Kasuga A, Aoyagi Y and Sugahara T: Antioxidative activities of several mushroom extracts. Jpn Soc Food Sci Technol 40: 56-63, 1993.

27. Lee Yu, Jian Shao, Lian Pei and Mau Jeng: Antioxidant properties of extracts from a white mutant of the mushroom Hypsizigus marmoreus. J Food Compos Anal 21: 116-124, 2008.

28. Du XJ, Zhang JS, Liu YF, Tang QJ, Jia Z, Yang Z and Pan YJ The antioxidant activity of various extracts from Tremella aurantialba fruiting bodies and their protective effects on PC 12 cells injured by oxidation. Acta Agri Shanghai 26: 49-52, 2010.

29. Su Z,DaiZ and Yang J: Research progress on immune mechanism of polysaccharide. J Yunnan Agri Univ 21: 205-209, 2006.

30. He Q and Zhang S: Advances in the studies on the mechanism of immuno-potentiation effect of polysaccharides from edible-medicinal fungi. Acta Edulis Fungi 11: 52-58, 2004 (In Chinese)

31. Du X, Zhang J, Yang Y, Ye L, Tang Q, Jia W, Liu Y, Zhou S, Hao R, Gong $\mathrm{C}$ and Pan Y: Structural elucidation and immuno-stimulating activity of an acidic heteropolysaccharide (TAPA1) from Tremella aurantialba. Carbohyd Res 344: 672-678, 2009.

32. Lee MY, Lee JA, Seo CS, Ha H, Lee H, Son JK and Shin HK: Anti-inflammatory activity of Angelica dahurica ethanolic extract on RAW264. 7 cells via upregulation of heme oxygenase-1. Food Chem Toxicol 49: 1047-1055, 2011.

33. Shin JY, Song JY, Yun YS, Yang HO, Rhee DK and Pyo S: Immunostimulating effects of acidic polysaccharides extract of Panax ginseng on macrophage function. Immunopharm immunot 24: 469-482, 2002.

34. Lee KY and Jeon YJ: Macrophage activation by polysaccharide isolated from Astragalus membranaceus. Int Immunopharmacol 5: 1225-1233, 2005.

35. Du X, Zhang J, Lv Z, Ye L, Yang Y and Tang Q: Chemical modification of an acidic polysaccharide (TAPA1) from Tremella aurantialba and potential biological activities. Food Chem 143: 336-340, 2014. 